\title{
In Vitro Selection of RNA Aptamers to a Protein Target by Filter Immobilization
}

While there are multiple possible configurations for in vitro selection experiments, this unit will describe one of the most common: selection of aptamers that bind to a protein target from a single-stranded RNA pool. Aptamers generated from these types of selection experiments can potentially function as protein inhibitors, and may find applications as therapeutic or diagnostic reagents. In short, a double-stranded DNA pool (see UNIT 9.2) will be transcribed to generate a single-stranded RNA pool (Basic Protocol 1). The initial concentration of protein target to be used is determined by labeling an aliquot of the pool (see Support Protocol 1) and performing the binding assay as described in Support Protocol 2. Following purification, the pool is mixed with the protein target. Binding species are separated from nonbinding species by filtration (see Basic Protocol 2). RNA:protein complexes are then eluted from the filter and binding species are amplified by a combination of reverse transcription, the polymerase chain reaction (PCR), and in vitro transcription (see Basic Protocol 3). The progress of the selection will be monitored by assaying the affinity of the radiolabeled RNA pool for the protein target after several rounds of selection (see Support Protocol 3). These steps are then repeated until a

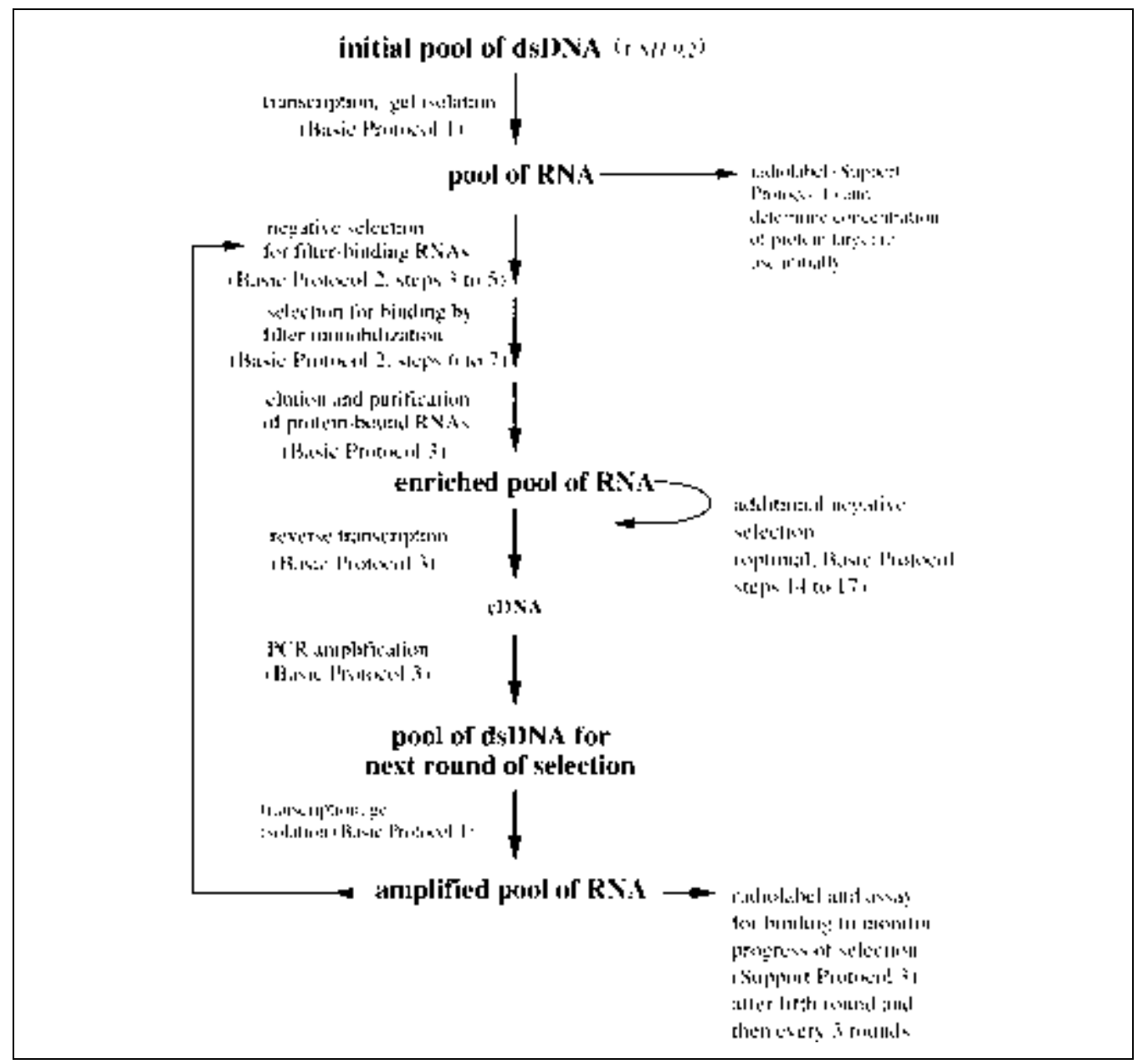

Figure 9.3.1 Steps involved in in vitro selection of RNA aptamers. 
BASIC PROTOCOL 1

significant increase in binding is observed or until the diversity of the pool has been completely plumbed. The procedure is summarized in Figure 9.3.1.

\section{TRANSCRIPTION AND ISOLATION OF RNA POOLS}

The following protocol describes the preparation of the RNA pool to be used for selection. Starting from the dsDNA pool, the RNA is transcribed and purified by denaturing polyacrylamide gel electrophoresis. Recovery of the RNA from the gel is followed by ethanol precipitation of the RNA. Additional instructions can be found in CPMB UNIT 3.8. The directions provided here are specific for the isolation of nucleic acid pools. As is the case for the original amplification of DNA pools (UNIT 9.2), many of the procedures described here can potentially lead to the cross-contamination of different RNA selection experiments or different generations of the same selection experiment. To avoid crosscontamination, it is wise to always use barrier tips and to use disposable plastic Pasteur pipets rather than automatic micropipettors for large-volume transfers.

\section{Materials}

Double-stranded DNA pool (UNIT 9.2)

Transcription mix (see recipe)

RNase-free DNase (e.g., RQ1 DNase; Promega)

$10 \%$ polyacrylamide denaturing gel (see recipe and APPENDIX $3 B$ )

$2 \times$ denaturing dye (see recipe)

TBE buffer (APPENDIX 2A)

$5 \mathrm{M} \mathrm{NaCl}$

$90 \%$ and $100 \%$ ethanol

TE buffer, $\mathrm{pH} 8.0$ (APPENDIX 2A)

$37^{\circ}$ to $42^{\circ} \mathrm{C}$ and $65^{\circ}$ to $75^{\circ} \mathrm{C}$ water baths

Fluorescent TLC plate (VWR) wrapped in plastic wrap

Spectrophotometer

Additional reagents and equipment for denaturing polyacrylamide gel electrophoresis (APPENDIX 3B)

NOTE: All solutions and buffers should be freshly treated with DEPC (APPENDIX 2A). Use sterile, disposable plasticware where possible. See APPENDIX $2 A$ for guidelines on standard methods to protect against contaminating RNases.

\section{Perform initial round of transcription}

Use the double-stranded DNA pool generated in UNIT 9.2 as a template for in vitro transcription with T7 RNA polymerase.

1. Add $\sim 1 \mu \mathrm{g}$ of double-stranded DNA template generated as in UNIT 9.2 to transcription mix for a $20 \mu \mathrm{L}$ total reaction volume. Incubate reaction overnight at $37^{\circ}$ to $42^{\circ} \mathrm{C}$.

Depending on the length and initial complexity of the pool, $1 \mu \mathrm{g}$ of double-stranded DNA will represent $\sim 10^{13}$ different sequences. The transcription reaction will yield $\sim 10$ to $50 \mu \mathrm{g}$ of RNA, and thus from 20 to 100 copies of each sequence originally present. If more RNA is desired for initial or subsequent rounds of selection, a proportionately larger transcription reaction should be attempted.

In Vitro Selection of RNA Aptamers to a Protein

The success of the transcription reaction can sometimes be monitored by observing the formation of a precipitate over time. This precipitate is likely a complex between magnesium and the pyrophosphate released from each polymerized ribotide. However, this rule is not absolute: many successful transcription reactions have no precipitate; some unsuccessful reactions have a precipitate. 
In general, though, the authors have found that much higher yields of RNA can be obtained from commercial transcription kits (e.g., Ampliscribe from Epicentre Technologies or Megashortscipt from Ambion) than from home-made in vitro transcription reactions. The use of such kits reduces the amount of time necessary to generate an adequate amount of transcript (1 to $4 \mathrm{hr}$ rather than overnight). Depending on the amount of RNA that is desired for each round of selection, such kits may also (surprisingly) represent a more cost-efficient alternative.

In some instances it will be desirable to radiolabel the RNA. For example, it is relatively easy to determine whether and how much RNA binds to a filter in the presence or absence of a protein target by radiolabeling the initial pool (Support Protocol 1). An [a- $\left.{ }^{32} P\right] n u-$ cleoside triphosphate-e.g., $0.5 \mu \mathrm{l}\left[\mathrm{a}^{32}{ }^{32}\right.$ P]UTP (NEN Life Science Products) in a 20- $\mu \mathrm{L}$ total volume - can be included in the reaction mixture in addition to all the other reagents. Varying the proportion of "hot" to "cold" nucleoside triphosphates can control the specific activity of the RNA pool. Since the overall yield of the transcription reaction will generally be important, the specific activity of the nucleoside triphosphate mixture should be varied by increasing the amount of radioactive nucleotide added, rather than by decreasing the amount of unlabeled nucleotide present. Again, commercial transcription kits can be obtained that are geared towards the incorporation of labeled nucleoside triphosphates (RiboScribe, Epicentre).

2. In order to remove DNA from the transcription reaction, after the transcription incubation has been completed, add 5 to $10 \mathrm{U}$ of RNase-free DNase and incubate 25 min at $37^{\circ} \mathrm{C}$.

Because individual members of the double-stranded DNA library can potentially bind nonspecifically to either the target or to the selection matrix and subsequently be amplified, the DNA template should be removed from the transcription reaction according to this step, prior to proceeding with the selection.

It is essential that RNase-free DNase, such as RQ1 DNase (Promega) be used, otherwise contaminating ribonucleases may destroy the newly transcribed RNA pool. An alternative would be to add RNase inhibitors to impure DNases, but such inhibitors themselves frequently contain endogenous ribonucleases that can be released during the incubation.

\section{Purify the RNA pool}

The RNA pool should generally be purified by denaturing gel electrophoresis

3. Prepare a $0.75-\mathrm{mm}$ thick, denaturing $10 \%$ acrylamide gel (see Reagents and Solutions and, e.g., APPENDIX $3 B)$.

A $10 \%$ acrylamide concentration is convenient for the purification of RNA molecules from 45 to 70 nucleotides in length. However, the concentration of acrylamide used to separate the full-length transcript from incomplete transcripts is ultimately contingent upon the size of the RNA and should be chosen so that the RNA will migrate approximately half-way through the gel when the loading dye has reached the bottom (see APPENDIX 3B).

If the RNA sample contains a significant amount of nascent structure (for example, a doped sequence population that is based on a tightly folded secondary structure) it may not fully denature. Thus, it may be advisable to warm the gel to $\sim 55^{\circ} \mathrm{C}$ by first pre-running the gel at a higher voltage (300 to $400 \mathrm{~V})$. The temperature of the gel can be monitored using adherent thermometers (VWR).

In some cases, very large amounts of RNA may need to be purified (for example, the initial transcription of an extremely complex DNA library may yield upwards of a milligram or more of an RNA library). In these instances, it may be desirable to purify the RNA library by either gel-filtration or ion-exchange chromatography (e.g., Qiagen RNA kit). However, the purification of the initial or subsequent pools should never be neglected, as foreshortened amplicons can arise and overtake selected populations.

Combinatorial Methods in Nucleic Acid Chemistry 
4. Fully denature the RNA pool by adding an equal volume of $2 \times$ denaturing dye, and heat the RNA-dye mix 3 min at $65^{\circ}$ to $75^{\circ} \mathrm{C}$.

Although each species in the pool has a different sequence and shape, they should migrate similarly when fully elongated.

Using a higher temperature or longer denaturing time risks hydrolysis of the RNA into smaller fragments by the high concentration of $\mathrm{Mg}^{2+}$ present in the transcription buffer.

5. Thoroughly rinse each well with TBE buffer using a plastic Pasteur pipet prior to loading (to remove urea, which will otherwise leach into the wells and form a barrier between the loaded sample and the gel). Load samples directly on the gel at 10 to 20 $\mu \mathrm{g}$ per 1-cm-wide lane (i.e., load a single transcription reaction in 2 to 3 lanes of the gel). Run electrophoresis for 1 to $2 \mathrm{hr}$ at 150 to $250 \mathrm{~V}$, until the bromophenol blue dye front reaches the bottom of the gel.

If the wells are not cleaned prior to loading, the resolution of the separation can be compromised, especially if large amounts of RNA are being isolated.

6. Visualize the RNA bands by UV shadowing on a fluorescent TLC plate covered with plastic wrap, then excise the bands. Be sure to cut with a sharp razor blade and cut only the shadowed regions that contain the bulk of the RNA.

There may be extra bands in the lane that correspond to incomplete transcripts or undigested DNA. The use of a size standard in a neighboring lane is recommended. Note, however, that the size standard should not itself be amplifiable, as cross-contamination of a single sequence with the RNA pool would drastically skew the distribution of sequences in the purified pool. Similarly, the razor blade used for excision should not have come into contact with other potentially amplifiable sequences, and should either be fresh or should have been cleaned extensively. Finally, if multiple selections are being carried out in parallel they should not be purified on the same gel.

7. Immerse the gel slices in RNase-free water at $\sim 400 \mu \mathrm{L}$ water $/ \mathrm{cm}^{2}$ of gel (typically, slices from 2 lanes) and incubate at $37^{\circ} \mathrm{C}$ overnight with agitation to elute the RNA pool.

For a quicker elution step, incubate the slices at $65^{\circ}$ to $75^{\circ} \mathrm{C}$ for $1 \mathrm{hr}$. However, the amount of RNA recovered will be lower, and there is a greater risk of degradation. The gel can be macerated to increase the speed or efficiency of recovery, but in this case small fragments of acrylamide may remain in the eluant. The eluate can be filtered through an $0.45-\mu \mathrm{m}$ nitrocellulose membrane to remove acrylamide fragments.

\section{Collect and quantitate the RNA}

8. Use a plastic Pasteur pipet to separate the RNA-containing eluate from the gel slice. Add $\mathrm{NaCl}$ (from $5 \mathrm{M}$ stock) to a final concentration of $0.3 \mathrm{M}$ and ethanol precipitate the RNA by adding 2 vol ethanol. Mix and incubate at $-20^{\circ} \mathrm{C}$ for $30 \mathrm{~min}$ or $-70^{\circ} \mathrm{C}$ for $10 \mathrm{~min}$. Microcentrifuge 20 to $40 \mathrm{~min}$ at maximum speed, $4^{\circ} \mathrm{C}$, to recover the precipitate.

Smaller RNA molecules (20 to nucleotides in length) can be more efficiently precipitated with 2.5 vol of ethanol.

The authors frequently include $1 \mu \mathrm{L}$ of a $1 \mathrm{mg} / \mathrm{mL}$ glycogen solution to increase the yield of nucleic acid precipitate and to better visualize the pellet. If the selection target binds to or interacts with glycogen, then this step should be omitted. Transfer RNA can also be used as a carrier, but will obfuscate the quantification of the pool RNA (see below).

In Vitro Selection of RNA Aptamers to a Protein Target by Filter Immobilization
9. Wash the RNA pellet with cold $90 \%$ ethanol and dry the pellet.

The pellet can be air dried, dried under a nitrogen or argon stream, or dried in a SpeedVac evaporator. The first method is least likely to result in cross-contamination of nucleic acid 
species; the last method is least likely to lead to degradation. In any event, keep the tube covered with Parafilm to avoid inadvertent nuclease contamination (poke holes in the Parafilm with a sterile needle to allow evaporation to proceed).

If the RNA pool is particularly short ( $\leq 50$ nucleotides) use cold $95 \%$ ethanol for the wash step.

10. Resuspend the RNA pellet in $25 \mu \mathrm{L}$ TE buffer, $\mathrm{pH}$ 8.0.

To avoid disturbing the composition of the selection buffer, the pellet can also be resuspended in RNase-free water (APPENDIX 2A). However, the small amount of EDTA present in TE buffer will limit ribonuclease degradation of the pool, since ribonucleases frequently require a divalent metal. In some instances, though (e.g., small-volume PCR reactions), the presence of EDTA may have to be compensated for by adding more magnesium to the reaction.

11. Estimate the quantity of the RNA photometrically by measuring the absorbance at $260 \mathrm{~nm}$.

Use an extinction coefficient of $0.025 \mathrm{~mL} \mathrm{~cm} \mathrm{~cm}^{-1} \mathrm{~g}^{-1}$ (see, e.g., CPMB APPENDIX 3D).In practical terms, measure the $A_{260}$ of a 1:500 dilution of the sample $(2 \mu \mathrm{L}$ dissolved in $1 \mathrm{~mL}$ RNase-free water) and multiply the absorbance by 20 to obtain the number of $\mu g / \mu L$ in the original sample. Do not attempt to calculate concentrations using absorbance readings less than $\sim 0.03$. The $A_{260} / A_{280}$ ratio should be somewhere between 1.8 and 2.2. Ratios outside of this range make the purity of the original RNA sample suspect (with residual acrylamide being the most likely contaminant), and the sample should be reprecipitated prior to use.

\section{RADIOLABELING THE RNA FOR USE IN AN INITIAL AFFINITY ASSAY}

Radioactive RNA can be generated either by incorporation of an $\left[\alpha-{ }^{32} \mathrm{P}\right]$ nucleoside triphosphate during transcription or by transfer of the terminal phosphate of $\gamma^{32} \mathrm{P}$ ATP to the $5^{\prime}$ terminus of a dephosphorylated RNA molecule. The authors tend to prefer the latter method, despite the additional labor involved in preparation, because the specific activity of the sample is higher, less RNA is required for assays, and dissociation constants are correspondingly easier to compute.

\section{Materials}

RNA pool (see Basic Protocol 1)

$10 \times$ alkaline phosphatase buffer (Boehringer Mannheim)

Calf alkaline phosphatase (Boehringer Mannheim)

1:1 phenol/chloroform (APPENDIX 2A)

Chloroform

$5 \mathrm{M} \mathrm{NaCl}$

$90 \%$ and $100 \%$ ethanol

$10 \times$ PNK buffer (New England Biolabs)

T4 polynucleotide kinase (PNK; New England Biolabs)

$167 \mathrm{mCi} / \mathrm{ml}\left[\gamma^{-32} \mathrm{P}\right]$ ATP $(7000 \mathrm{Ci} / \mathrm{mmol} ; \mathrm{ICN})$

$4 \mathrm{M}$ ammonium acetate

$42^{\circ}$ and $75^{\circ} \mathrm{C}$ water baths

NOTE: All solutions and buffers should be freshly treated with DEPC (APPENDIX 2A). Use sterile, disposable plasticware where possible. See APPENDIX $2 A$ for guidelines on standard methods to protect against contaminating RNases. 
Dephosphorylate the $5^{\prime}$ triphosphate termini of the isolated RNA pool

1. Mix the following components:

$1 \mu \mathrm{g}$ RNA in $<3.5 \mu \mathrm{L}$ volume

$0.5 \mu \mathrm{L} 10 \times$ alkaline phosphatase buffer

$1 \mu \mathrm{L}(1 \mathrm{U})$ calf alkaline phosphatase

$x \mu \mathrm{L}$ RNase-free water for a total reaction volume of $5 \mu \mathrm{L}$.

The RNA sample may need to be reprecipitated to obtain an adequately concentrated sample. If so, the precipitate can be resuspended directly in the reaction buffer or mixture.

Calf alkaline phosphatase is preferred over bacterial alkaline phosphatase because the activity can be heat-killed (see step 4) prior to the addition of the radiolabel.

2. Incubate at $42^{\circ} \mathrm{C}$ for $20 \mathrm{~min}$ to $2 \mathrm{hr}$.

3. Add $95 \mu \mathrm{L}$ RNase-free water.

4. Heat denature the calf alkaline phosphatase $10 \mathrm{~min}$ at $75^{\circ} \mathrm{C}$.

5. Perform a phenol/chloroform extraction (see Basic Protocol 2, step 10).

If the sample will be gel-isolated, this step can be omitted. If the radiolabeled sample will merely be precipitated prior to use, this step should be included.

6. Ethanol precipitate the RNA in the presence of $0.3 \mathrm{M} \mathrm{NaCl}$ and wash the pellet with 90\% ethanol (see Basic Protocol 1, steps 8 and 9).

Avoid precipitating RNA in the presence of ammonium acetate since ammonium ions inhibit the T4 polynucleotide kinase used in the next step.

7. Resuspend the dried pellet in a minimal volume (3 to $10 \mu \mathrm{l}$ ) of RNase-free water.

\section{Perform kinase reaction}

8. Set up the kinase reaction as follows:

0.5 to $3 \mu \mathrm{L}$ dephosphorylated RNA pool (from step 7)

$0.5 \mu \mathrm{L} 10 \times$ PNK buffer

$1 \mu \mathrm{L}(10 \mathrm{U}) \mathrm{T} 4$ polynucleotide kinase (PNK)

$0.5 \mu \mathrm{L}(83 \mu \mathrm{Ci})\left[\gamma_{-}{ }^{32} \mathrm{P}\right] \mathrm{ATP}(7000 \mathrm{Ci} / \mathrm{mmol}, \mathrm{ICN})$

$x \mu \mathrm{L} \mathrm{RNase-free} \mathrm{H}_{2} \mathrm{O}$ for a total volume of $5 \mu \mathrm{L}$.

Only a very small amount of RNA will be used in the binding assay ( 50 pM in a $100 \mu \mathrm{L}$ reaction). Unless multiple experiments are contemplated, the specific activity of the sample can be kept quite high by using a very small amount of RNA in the kinase reaction.

9. Incubate for $1 \mathrm{hr}$ at $37^{\circ} \mathrm{C}$.

10. Add $95 \mu \mathrm{L}$ RNase-free water.

If the sample will be gel-isolated, this step can be omitted.

11. Perform a phenol/chloroform extraction (see Basic Protocol 2, step 10).

If the sample will be gel-isolated, this step can be omitted.

of RNA Aptamers

to a Protein

Target by Filter

Immobilization

12. Ethanol precipitate the RNA in the presence of $2.0 \mathrm{M}$ ammonium acetate (i.e., by adding an equal volume of $4.0 \mathrm{M}$ ammonium acetate). 
The use of ammonium acetate inhibits the precipitation of nucleotides and small transcripts. However, if the RNA pool is short, the precipitation may also be inefficient. If the sample will be gel-isolated, then this step can be omitted.

13. Optional: In order to fully separate the radiolabeled RNA pool from unincorporated nucleotides, partially degraded transcripts, and enzymes, isolate the transcript as described in Basic Protocol 1, steps 3 to 9).

If this is done, the phenol/chloroform extractions and the final precipitation of the RNA (steps 10 to 12 of this protocol) can be omitted. The chief disadvantages of gel isolation are the time required for sample preparation and the relatively low efficiency of recovery of the radiolabeled RNA pool. However, since only a small amount of RNA pool is required for the binding assay such low yields can frequently be tolerated. The authors frequently gel isolate radiolabeled RNA pools to ensure the integrity of RNA samples prior to carrying out binding assays.

\section{BINDING ASSAY WITH THE END-LABELED RNA POOL TO DETERMINE THE OPTIMAL PROTEIN CONCENTRATION FOR SELECTION}

To determine the initial concentration of a protein target to be used in a selection experiment, it is necessary to measure the affinity of the unselected pool for the protein target (for theoretical considerations, see UNIT 9.1). The aggregate dissociation constant of the pool:protein complex can be calculated by determining the fraction of radioactively labeled RNA that can be bound at various protein concentrations.

The radiolabeled RNA is incubated in the binding buffer and protein solutions are added. The binding reaction is filtered through a vacuum manifold containing nitrocellulose and nylon membranes and the fraction of RNA bound to the target is calculated to obtain a value for the dissociation constant. The nitrocellulose membrane will capture RNA:protein complexes, while the nylon membrane will capture all free RNA that flows through the nitrocellulose membrane.

\section{Materials}

Radiolabeled RNA pool (Support Protocol 1)

Binding buffer (see Critical Parameters)

Target protein

$65^{\circ}$ to $75^{\circ} \mathrm{C}$ water bath

Milliblot apparatus (Schleicher \& Schuell)

Nylon transfer membrane (Hybond N+, Amersham Pharmacia Biotech)

$0.45-\mu \mathrm{m}$ nitrocellulose transfer and immobilization membrane (Midwest Scientific)

Glass plate

Phosphorimager (Molecular Dynamics) and screen or X-ray film and densitometer Graphing software (e.g., Kaleidograph from Synergy Software)

NOTE: All solutions and buffers should be freshly treated with DEPC (APPENDIX 2A). Use sterile, disposable plasticware where possible. See APPENDIX $2 A$ for guidelines on standard methods to protect against contaminating RNases.

\section{Set up binding reactions}

1. Collect the RNA precipitate by centrifugation and resuspend the radiolabeled RNA in a minimal volume (i.e., 5 to $10 \mu \mathrm{L}$ ) of RNase-free water. Dilute the RNA sample with binding buffer to a final concentration of $100 \mathrm{pM}$. 
The concentration can be very roughly estimated by assuming full recovery of the RNA sample. Differences between estimated and actual concentrations are less important because the RNA sample will be limiting relative to the amount of protein sample present in the binding reaction.

The binding assay will yield 11 data points in triplicate (see below). Since each data point will be generated from a 50- $\mu \mathrm{L}$ binding reaction, $2 \mathrm{~mL}$ of the RNA solution should be adequate. If the specific activity of the RNA is not high enough, a higher concentration of RNA may be used, but that will complicate the assumption that RNA is limiting and hence the calculation of the $K_{\mathrm{d}}$.

2. To ensure that each species in the RNA pool folds into the most accessible or most stable conformation, heat the RNA pool in $25-\mu \mathrm{L}$ binding buffer to $65^{\circ}$ to $75^{\circ} \mathrm{C}$ for $3 \mathrm{~min}$ and then allow the sample to cool to room temperature over $\sim 10 \mathrm{~min}$.

3. Add $25 \mu \mathrm{L}$ of the protein target in binding buffer to the thermally equilibrated RNA from step 2. Use ten different protein concentrations ranging from $1 \mu \mathrm{M}$ to $50 \mathrm{pM}$. Also include one data point with no protein to measure the filter-binding ability of the pool itself.

The original protein solution should be sufficiently concentrated for all of the dilutions. To ensure consistency between samples, serial dilutions of the $1 \mu \mathrm{M}$ sample can be made. The authors suggest the following concentrations: $1 \mu \mathrm{M}, 333 \mathrm{nM}, 111 \mathrm{nM}, 37 \mathrm{nM}, 12 \mathrm{nM}, 4.1$ $n M, 1.4 \mathrm{nM}, 460 \mathrm{pM}, 152 \mathrm{pM}, 51 \mathrm{pM}$, (i.e., $1 \mu \mathrm{M}$, and subsequent 1/3 dilutions) and a "no protein" control. For statistically significant results perform the binding assay in triplicate.

4. Incubate the binding reaction at room temperature for $15 \mathrm{~min}$ to $1 \mathrm{hr}$ (see Critical Parameters).

\section{Perform filter binding}

5. Assemble the Milliblot apparatus (Fig. 9.3.2). Lay the nylon transfer membrane on top of the perforations in the middle section. Moisten the nylon membrane and lay the nitrocellulose membrane on top of the nylon membrane, taking care to avoid the formation of bubbles between the two membranes. Cover and tighten the brackets.

Prior to filtering the binding reactions, wash the wells that will be used with binding buffer and check for leaks. When the manifold is used in conjunction with an aspirator, turn the

In Vitro Selection of RNA Aptamers to a Protein Target by Filter Immobilization

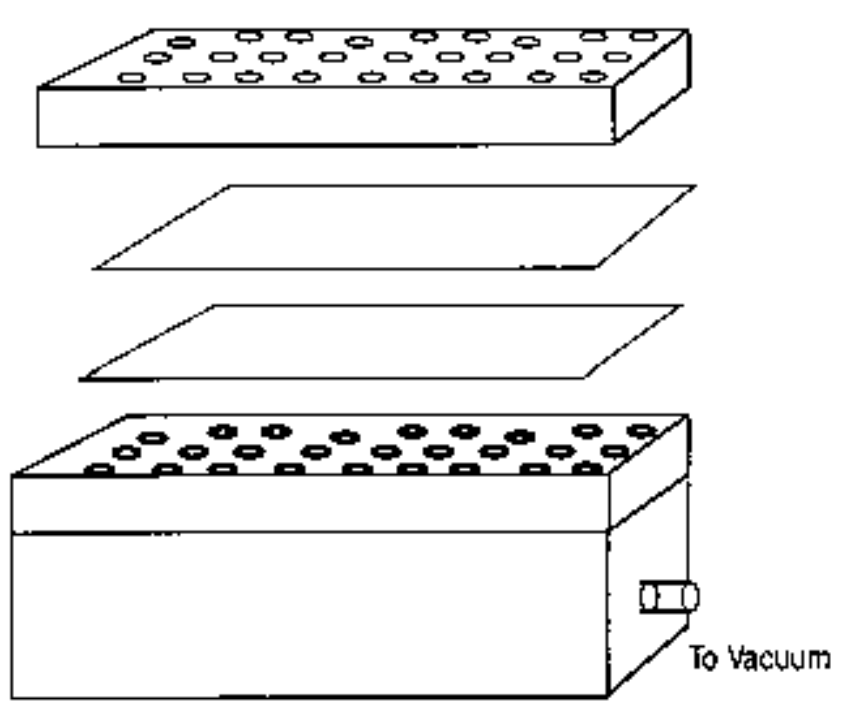

Figure 9.3.2 Assembly of the Milliblot apparatus used for binding assays. 
water faucet to a level that causes liquid to pass slowly through the membranes (i.e., 100 $\mu L$ every $3 \mathrm{sec}$ ).

Since there are so many binding reactions, it is more convenient to use a manifold apparatus that can accommodate multiple filtrations (up to 96 slots) than to assemble 33 individual filter holders.

6. Filter the binding reactions and wash three times with binding buffer.

When pipetting onto the manifold, dispense the liquid slowly and evenly. Try to keep the membrane constantly hydrated during each wash step. Keep the pipet tip close to the membrane to avoid bubble formation, but not so close as to risk damaging the membrane.

7. Disassemble the manifold apparatus and transfer the membranes to a clean paper towel. Air dry for $\sim 5 \mathrm{~min}$. Handle membranes with a clean pair of forceps or tweezers.

The forceps or tweezers can be quickly cleaned with ethanol and RNase-free water prior to contacting the filters.

8. Transfer the membranes to a glass plate, cover with plastic wrap, and expose to a phosphor screen (e.g., Phosphorimager) or X-ray film for 4 to $12 \mathrm{hr}$.

If the samples have a very high specific activity, the exposure time can be reduced to 5 to $60 \mathrm{~min}$.

9. Measure the radioactivity using the Phosphorimager or a densitometer if X-ray film was used to develop the image, and calculate the binding percentages as follows:

Fraction bound $=\mathrm{cpm}$ on nitrocellulose/(cpm on nitrocellulose $+\mathrm{cpm}$ on nylon) If X-ray film was used to develop the image, then a digitizer (densitometer) should yield similar results to those obtained with a Phosphorimager.

10. Plot the fraction bound as a function of the concentration of unbound protein. Fit the points to a curve using graphing software (e.g., Kaleidograph) and obtain a value for the aggregate parent dissociation constant. Within the Kaleidograph program, fit the curve using the equation $y=m_{1} m_{0} /\left(m_{0}+m_{2}\right)$, where $y=$ the fraction of RNA bound, $m_{0}=$ concentration of unbound protein, $m_{1}=$ the extrapolated activity of the RNA at an infinite protein concentration (maximal value of fraction bound), and $m_{2}=$ the apparent dissociation constant.

The apparent $K_{\mathrm{d}}$ is equal to the concentration of unbound protein at half the maximal value of fraction bound.

\section{ISOLATING A FUNCTIONALLY ENRICHED POOL}

In the following protocol, the RNA pool is partitioned to isolate those species that bind to the target protein and not to the filter. RNAs that are coimmobilized with the target are eluted off the filter under denaturing conditions and subsequently isolated and amplified.

\section{Materials}

RNA pool (see Basic Protocol 1)

Binding buffer (see Critical Parameters)

Elution buffer (see recipe)

1:1 phenol/chloroform (see APPENDIX 2A), ice-cold

Chloroform

Isopropanol

$65^{\circ}$ to $75^{\circ} \mathrm{C}$ and $100^{\circ} \mathrm{C}$ water baths

Filter holders (Nuclepore)

BASIC

PROTOCOL 2

Combinatorial

Methods in

Nucleic Acid

Chemistry 
13-mm, 0.45- $\mu \mathrm{m}$ HAWP nitrocellulose disk filters (Millipore)

5 -ml syringe

Vacuum manifold

NOTE: All solutions and buffers should be freshly treated with DEPC (APPENDIX 2A). Use sterile, disposable plasticware where possible. See APPENDIX $2 A$ for guidelines on standard methods to protect against contaminating RNases.

\section{Partition the pool}

1. Use $\sim 5 \mu \mathrm{g}$ of the RNA pool ( $\sim 10^{13}$ to $10^{14}$ sequences $)$ for selection.

Using significantly lower quantities of RNA may affect the diversity of the population in the initial rounds of selection. Using significantly higher quantities may lead to precipitation of the nucleic acid pool. Irvine et al. (1991) have devised a formula to determine the optimum protein and RNA concentration in order to minimize the number of rounds of selection, based on the $K_{\mathrm{d}}$ of the starting pool, the desired $K_{\mathrm{d}}$, and the fraction of free $R N A$ molecules that partitions as nonspecific background versus the fraction of RNA molecules that forms specific RNA:protein complexes. Refer to UNIT 9.1 for additional details. Empirically, the concentrations of many available protein targets will be in the nanomolar range, and a 1-to 10-fold excess of the RNA pool should suffice for early rounds of selection.

If only a small amount of RNA pool is initially recovered from the gel, be sure to save at least some sample for the "no protein" control (see below).

2. To ensure that each species in the RNA pool folds into the most accessible or most stable conformation, heat the RNA pool in 50 to $100 \mu \mathrm{L}$ binding buffer (see Critical Parameters for discussion on choosing a binding buffer) to $65^{\circ}$ to $75^{\circ} \mathrm{C}$ for $3 \mathrm{~min}$ and then allow the sample to cool to room temperature over $\sim 10 \mathrm{~min}$.

Since ionic strength, monovalent and divalent cation concentrations, $\mathrm{pH}$, temperature, and buffer concentrations can all influence interactions with the target, it is usually wise to keep all of these parameters constant during the early rounds of selection when productive binding species are accumulating. Hence, the binding buffer, equilibration time, and preparation of the RNA for selection should be kept uniform until a significant interaction between pool and target is observed (see Critical Parameters for discussion of stringency of selection).

Higher temperatures can be used for thermal equilibration, but the presence of divalent metal ions in the selection buffer can lead to RNA degradation.

3. Prior to the addition of the protein target, perform a negative selection to remove any filter-binding species that may be in the population. Moisten a filter disk with buffer and lock it into a filter holder (Fig. 9.3.3).

Negative selection to remove filter-binding species is an extremely important step in the selection procedure. Filter-binding species are typically more numerous in a naive RNA population than are aptamers. If filter-binding species are not efficiently sieved from the population, they will quickly accumulate to the point where it may be difficult (and likely impossible) to select protein-binding species. If the potential for accumulating filter-binding species is large (i.e., the target has a low initial affinity for a pool, or selections with DNA pools), then repeat the preselection filtration to remove any filter-binding species that may persist or carry out a post-selection filtration (see optional steps 14 to 17, below). If filter-binding species do accumulate during a selection experiment, it is usually wisest to repeat the selection starting with a different pool that can be amplified with different primers.

In Vitro Selection of RNA Aptamers to a Protein

In addition to filter-binding species, replication parasites (see Critical Parameters for discussion on parasites) can accumulate in and overrun a selected population. A separate regime is required to avoid these selection predators. 


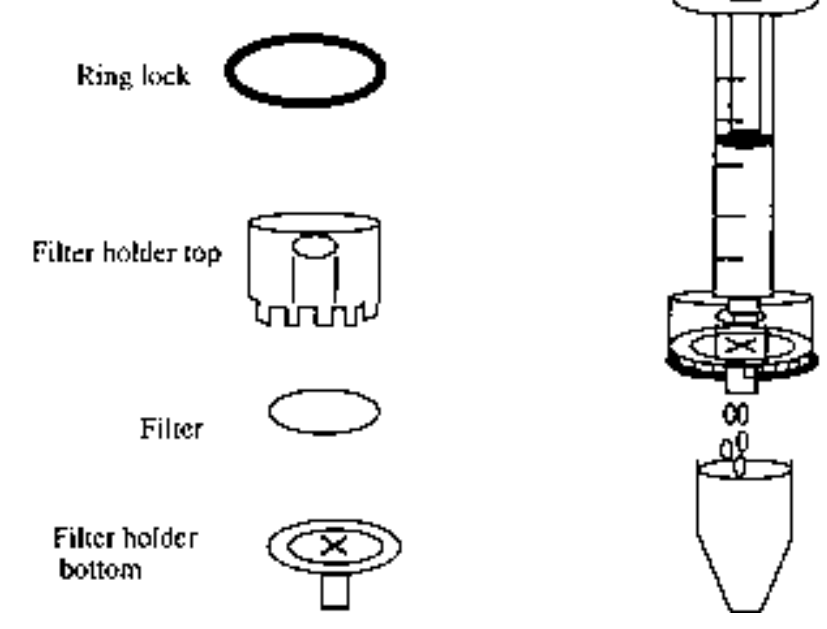

Figure 9.3.3 Components and assembly of filter holder used during selection.

4. Load the binding buffer onto the filter. Place the pipet tip just above the filter to avoid the formation of any bubbles. Lock a 5-ml syringe to the top of the filter holder and apply gentle pressure to force the liquid out of the filter holder and into a collecting tube.

Prior to filtering the RNA, it is important to wash the nitrocellulose filter disk with binding buffer and check for leaks in the assembled filter holder. The syringe should form a tight seal with the filter holder. The pressure applied should be just enough to force the liquid through without rupturing the membrane. The formation of foam at the bottom of the filter holder or the presence of a hissing sound when pressure is applied indicates that the pressure is too high, and the integrity of the seal or the membrane may have been breached. Test for leaks every time the filter holder is assembled in order to avoid substantial loss of sample.

5. Load the RNA solution onto the filter. Place the pipet tip just above the filter to avoid the formation of any bubbles. Lock a 5-ml syringe to the top of the filter holder and apply gentle pressure to force the liquid out of the filter holder and into a collecting tube.

Since there will still be some amount of liquid retained by the filter and filter holder, it is necessary to wash the filter with an equal amount of binding buffer to maximize the collection of non-filter-binding species. Discard the filter.

Table 9.3.1 Progress of N30 Selection Against bFGF ${ }^{a}$

\begin{tabular}{cccccc}
\hline Round & $\begin{array}{c}\text { Input (RNA) } \\
\text { nM }\end{array}$ & $\begin{array}{c}\text { Input (BFGF) } \\
\text { nM }\end{array}$ & (RNA):(bFGF) & $\begin{array}{c}\text { \% bound to } \\
\text { protein }\end{array}$ & $\begin{array}{c}\text { \% bound to } \\
\text { filter }\end{array}$ \\
\hline 1 & 800 & 760 & 1.05 & 2.1 & 2.3 \\
2 & 800 & 760 & 1.05 & - & - \\
3 & 800 & 76 & 10.5 & - & - \\
4 & 800 & 76 & 10.5 & 6.0 & - \\
5 & 800 & 13 & 61.5 & - & 0.4 \\
6 & 800 & 13 & 61.5 & 17.0 & - \\
\hline
\end{tabular}

${ }^{a}$ Pools were assayed in a 50- $\mu \mathrm{L}$ reaction at a concentration of $75 \mathrm{nM}$ in the presence and absence of equimolar protein.

Combinatorial

Methods in

Nucleic Acid Chemistry 
6. Add the protein target and any competitors, specific and/or non-specific, to the filtrate. Allow the binding reaction to equilibrate.

In selection experiments that targeted the cytokine bFGF, the authors used an equimolar protein-to-RNA ratio for the first two rounds of selection and decreased it 10-fold after two rounds and 60-fold after another two, yielding a functionally-enriched pool after 6 rounds of selection and amplification (Table 9.3.1). The final volume of the binding reaction should be from 100 to $200 \mu \mathrm{L}$. In addition, to ensure that the selected RNAs are actually binding to the target and not to the filter, a parallel binding reaction in the absence of protein can be carried out intermittently. The authors strongly suggest that "no protein" controls be scrutinized after $0,5,8$, and 11 rounds of selection.

The choice of selection conditions is probably the second most important determinant (following the choice of target) for whether a selection experiment will succeed or fail. While general guidelines for modulating the stringency of selection can be recommended (see Critical Parameters for comments on the stringency of selection), every target and every selection are different and no precise guidelines for success can be provided. In general, the stringency of selection should be lower in the early rounds of selection and higher in the later rounds. This will give binding species an opportunity to establish themselves in the population relative to filter-binding species.

It should be noted that there is some danger of cross-contaminating the selected pool with the "no protein" control. Basically, executing the "no protein" control is identical to selecting for protein-independent (filter) binding species, hence DNA arising from the "no protein" control should be handled with care.

7. Attach the filter holder to a vacuum manifold (which is used here to maintain a constant negative pressure during filtration, so that each round of selection is similar and reproducible). Apply a negative pressure of $5 \mathrm{in}$. of $\mathrm{Hg}$ to the filter holder. Pipet the binding reaction directly onto the filter with the tip just above the filter, avoiding the formation of bubbles, which may lead to an uneven application of the sample to the filter and impede the flow of liquid through the filter. Wash the filter with 3 vol of binding buffer.

Varying the strength of the vacuum, uneven application of the sample, and formation of bubbles during wash steps may result in inefficient sieving of binding from nonbinding species, and hence may reduce the efficiency of an individual round of selection. However, the selection as a whole is fairly robust with respect to changes in these parameters. In other words, even if steps are not performed perfectly, the selection can be carried forward.

\section{Elute RNA off the filter}

8. Remove the filter containing RNA:protein complexes from the filter holder using sterile forceps and place it in a 1.5-mL microcentrifuge tube. Transfer the filter quickly, in order to avoid ribonuclease contamination from the surrounding environment.

9. Add $200 \mu \mathrm{L}$ of elution buffer and heat for $5 \mathrm{~min}$ at $100^{\circ} \mathrm{C}$ to elute RNA molecules from the protein and filter. Remove the eluate to a tube and repeat with fresh elution buffer.

Two shorter, smaller-volume elutions will more efficiently recover intact RNA than one long, large-volume elution.

In Vitro Selection of RNA Aptamers to a Protein Target by Filter Immobilization

10. To remove residual peptide fragments or proteins that may have coeluted with the RNA, add an equal volume (i.e., $400 \mu \mathrm{l}$ ) of cold, 1:1 phenol/chloroform. Vortex, then microcentrifuge $1 \mathrm{~min}$ at maximum speed to separate the liquid phases (the RNA should be in the top, aqueous phase). Transfer the aqueous phase to a new $1.5-\mathrm{mL}$ microcentrifuge tube. 
Avoid transferring phenol/chloroform with the aqueous layer, as it can interfere with subsequent enzyme reactions. Nevertheless, the aqueous phase will sometimes appear milky, especially at low temperatures, due to the presence of dissolved phenol-chloroform.

11. Extract the eluate with a similar volume of chloroform to remove any residual phenol.

Avoid transferring chloroform with the aqueous layer, as it can interfere with subsequent enzyme reactions.

12. Dilute the eluate with an equal volume $(\sim 400 \mu \mathrm{L})$ of RNase-free water and add 800 $\mu \mathrm{L}$ of isopropanol, then chill $20 \mathrm{~min}$ at $-20^{\circ} \mathrm{C}$ to precipitate.

A carrier such as glycogen can be added to aid precipitation.

The elution buffer contains a high concentration of urea. Dilution with $400 \mu \mathrm{L}$ water and precipitation with isopropanol is necessary to avoid the formation of salt precipitates, which appear as oily, unstable droplets in the bottom of the microcentrifuge tube following centrifugation. If such "salt pellets" appear, additional water should be added to the sample, the mixture should be homogenized, and the precipitation repeated.

13. Microcentrifuge $30 \mathrm{~min}$ at maximum speed, remove the supernatant, and resuspend the RNA sample in $12 \mathrm{ml}$ sterile RNase-free water.

\section{Perform an additional negative selection (optional steps)}

An extremely effective method for ridding the population of filter-binding species is to carry out an additional negative selection following the selection for binding species, but prior to amplification. However, at early stages of the selection, an additional post-selection filtration step may reduce the complexity of the selected population. Therefore, it is recommended that post-selection filtration only be carried out following the second round of selection. Post-selection filtration can also be used to successfully remove filter-binding species that have begun to accumulate and overrun a selected population. However, once filter-binding species have established themselves, even a combination of pre- and post-selection filtrations may not allow specific binding species to regain a selective advantage. If a simple regime of pre- and post-filtration negative selections does not succeed in drastically reducing or eliminating established filter-binding species, the selection should be repeated with a different RNA pool that can be amplified with different primers, as recommended above.

14. Resuspend the selected RNA pellet in $50 \mu \mathrm{L}$ binding buffer.

15. Assemble the filter holder with a fresh filter disk as described above.

16. Filter the sample and wash as described above.

17. Discard the filter disk and ethanol precipitate the RNA filtrate.

A carrier (glycogen) can be added to improve the efficiency of precipitation.

If the binding buffer contains a high $(>0.5 \mathrm{M})$ salt concentration, dilute the filtrate with an equal volume of RNase-free water and precipitate with isopropanol instead.

\section{AMPLIFYING SELECTED BINDING SPECIES}

In the following steps, RNA species that survived the positive and negative selection steps are reverse transcribed to generate a cDNA library, which is subsequently amplified by PCR. The double-stranded DNA resulting from these steps comprises the pool from which the next round of selection will begin. While the authors have found that reverse transcription and PCR steps can be combined (steps 1a to 3a) for some of our selections, this is not universally true. To obtain the highest yield of RNA and DNA products, it is frequently desirable to carry out separate reverse transcription and PCR reactions (steps $1 \mathrm{~b}$ to $3 \mathrm{~b}$ ).

BASIC PROTOCOL 3

Combinatorial Methods in Nucleic Acid Chemistry 


\section{Materials}

Selected RNA pool (Basic Protocol 2)

TE buffer, pH 8.0, or RNase-free water

RT-PCR mix (see recipe)

$10 \times$ RT buffer (see recipe)

$20 \mu \mathrm{M} 3$ '-end primer

$20 \mu \mathrm{M} 5^{\prime}$-end primer

PCR mix (see recipe)

$4 \mathrm{mM}$ dNTP mix (APPENDIX 2A)

AMV reverse transcriptase (USB)

$6 \times$ nondenaturing dye: $0.6 \%$ bromphenol blue in TBE buffer

$4 \%$ NuSieve agarose gel (FMC Bioproducts; also see e.g., CPMB UNIT 2.6)

$10 \mu \mathrm{g} / \mathrm{mL}$ ethidium bromide solution (APPENDIX 2A)

TBE buffer (APPENDIX 2A)

$4 \mathrm{M}$ ammonium acetate

$100 \%$ ethanol

Thermal cycler (e.g., MJ Research)

Additional reagents and equipment for the polymerase chain reaction ( $C P M B$

Chapter 15) and agarose gel electrophoresis (e.g., CPMB UNIT 2.6)

NOTE: All solutions and buffers should be freshly treated with DEPC (APPENDIX 2A). Use sterile, disposable plasticware where possible. See APPENDIX $2 A$ for guidelines on standard methods to protect against contaminating RNases.

\section{Amplify selected binding species}

To amplify selected binding species via combined RT-PCR reactions

1a. Resuspend the RNA in $12 \mu \mathrm{L}$ TE buffer or RNase-free water and add $4 \mu \mathrm{L}$ of this RNA suspension to $96 \mu \mathrm{L}$ RT-PCR mix.

Since only $1 / 3$ of the total sample recovered is used for amplification this will obviously restrict the proportion of successful species that are carried into the next round of selection. This is only a potential problem in the early rounds of selection. For example, if the diversity of the RNA pool was such that each species was represented only a few times on average, then a population bottleneck is unavoidable. For this reason, it is always desirable to start with an RNA pool in which each species is represented numerous times. However, the amount of sample that is committed to amplification should probably not exceed one-half to two-thirds of the sample. If the reverse transcription or any subsequent steps are unsuccessful, then the archived RNA serves as an inviolate reservoir for proceeding forward in the selection experiment. Otherwise, one will have to return to material from an earlier round.

2a. Run the following controls in parallel with the amplification of selected RNA species in order to detect nonspecifically bound RNA species and replication parasites (see Critical Parameters for discussion of parasites).

a. No template control: To ensure that none of the stock solutions have been contaminated with exogenous RNA or DNA amplicons, set up a RT-PCR reaction without adding any template.

b. No RT control: To ensure that amplified products are in fact derived from selected RNA species and not from endogenous or cross-contaminating DNA molecules, set up a RT-PCR reaction without the reverse transcriptase.

In Vitro Selection of RNA Aptamers to a Protein

3a. Run the RT-PCR reaction on the thermal cycler as follows:

a. $10 \mathrm{~min}$ at $65^{\circ} \mathrm{C}$ 
b. $10 \mathrm{~min}$ at $50^{\circ} \mathrm{C}$

c. $45 \mathrm{sec}$ at $94^{\circ} \mathrm{C}$

d. $60 \mathrm{sec}$ at $50^{\circ} \mathrm{C}$

e. $90 \mathrm{sec}$ at $72^{\circ} \mathrm{C}$.

Repeat steps c to e six more times, then follow with:

f. $150 \mathrm{sec}$ at $72^{\circ} \mathrm{C}$.

Step a allows for primers to anneal to the RNA, while step $b$ allows the RT to generate cDNA. Steps c through e comprise the PCR cycle, and the final elongation step $(f)$ at $72^{\circ} \mathrm{C}$ completes the extension of any incomplete DNA templates. The number of cycles that should initially be carried out is considered below.

It should be noted that the listed conditions have been optimized for the pool used in the selections described, the N30 pool. Different pools and primers may require very different amplification conditions. (see CPMB UNIT 15.4 for comments on primer selection and, for the experimental parameters that govern reverse transcription and PCR).

If using a PCR machine without a heated bonnet, cover the amplification reaction with mineral oil (e.g., Mallinckrodt). In order to avoid the accumulation of replication parasites, it may be desirable to use one of a number of "hot-start" methods for the PCR reaction (see CPMB Chapter 15). The technically simplest of these is to add reverse transcriptase following heating to $65^{\circ} \mathrm{C}$ in step a, and to add Taq or another thermostable polymerase following heating to $94^{\circ} \mathrm{C}$ in step $\mathrm{c}$.

To amplify selected binding species via separate $R T$ and $P C R$ reactions

1b. Resuspend the RNA in $12 \mu \mathrm{L}$ TE buffer or RNase-free water, and set up the RT reaction as follows:

$4 \mu \mathrm{L}$ RNA, diluted as described above

$2 \mu \mathrm{L} 10 \times$ RT buffer

$10 \mu \mathrm{L} 20 \mu \mathrm{M} 3^{\prime}$-end primer

$4 \mu \mathrm{L} 4 \mathrm{mM}$ dNTP mix

$0.3 \mu \mathrm{L}$ (10 U) AMV reverse transcriptase.

Also set up "no template" control without the RNA template and "no RT" control without the reverse transcriptase.

2b. Incubate reactions $30 \mathrm{~min}$ at $42^{\circ} \mathrm{C}$.

3b. Add $10 \mu \mathrm{L}$ of each RT reactions to an individual tube containing $100 \mu \mathrm{L}$ PCR mix. Conduct the PCR reaction as follows:

a. $45 \mathrm{sec}$ at $94^{\circ} \mathrm{C}$

b. $60 \mathrm{sec}$ at $50^{\circ} \mathrm{C}$

c. $90 \mathrm{sec}$ at $72^{\circ} \mathrm{C}$.

Repeat steps a and b six more times, then follow with:

d. $150 \mathrm{sec}$ at $72^{\circ} \mathrm{C}$.

See, e.g., CPMB UNIT 15.1 for additional information on PCR amplification.

\section{Check for the presence of amplified, double-stranded DNA}

4. Add $1.5 \mu \mathrm{L}$ of $6 \times$ non-denaturing dye to 5 to $10 \mu \mathrm{L}$ of the PCR reaction. Load the sample onto a $4 \%$ NuSieve agarose gel which has been presoaked in $10 \mu \mathrm{g} / \mathrm{mL}$

Combinatorial Methods in Nucleic Acid Chemistry 
ethidium bromide solution for $10 \mathrm{~min}$ (e.g., СPMB UNIT 2.6). Run the gel in TBE at 125 V for 15 min. Look for products with a hand-held UV lamp or UV light box.

An estimate of the minimal number of cycles needed to visualize a product band on the agarose gel can be roughly calculated. Consider that, of the $5 \mu \mathrm{g}$ of RNA added to the selection, $\sim 3 \%$ likely binds to the filter and is lost during the negative selection step. Approximately $1 \%$ of the population may bind to the target. When the selected RNA is precipitated, one-third of the sample is used for RT-PCR. Therefore:

$(5.0 \mu g)(0.97)(0.01) / 3=0.016 \mu g$ RNA.

Assuming that every thermal cycle doubles the amount of DNA, a minimum of seven thermal cycles would be necessary to obtain 1 to $2 \mu \mathrm{g}$ of DNA. This would imply that 0.1 to $0.2 \mu \mathrm{g}$ could be loaded and readily visualized on the ethidium bromide-stained agarose gel. Thus, from 7 to 8 thermal cycles should initially be carried out and the products analyzed by gel electrophoresis. The authors frequently find this rough estimate to be true.

5. If no product bands are apparent, then carry out an additional 4 to 5 thermal cycles and again analyze the products by gel electrophoresis. If only faint product bands are apparent, then one may want to accumulate additional template via an additional 2 to 4 thermal cycles.

The accumulation of double-stranded DNA is closely monitored in order to avoid "over$P C R$ " of the sample and the concomitant accumulation of high-molecular-weight species. DNA that has been over-amplified will look blurry and disperse following analysis by gel electrophoresis. These large DNA molecules are often the result of the $3^{\prime}$ end of a single-stranded DNA folding back and internally priming its own extension, resulting in a long stem-loop that can be amplified by a single PCR primer (also known as single-primer artifacts). Overamplified DNA templates can also yield RNA molecules of the incorrect size following transcription. Adding $2 \mu \mathrm{L}$ of the RT-PCR reaction to $100 \mu \mathrm{L}$ of a fresh PCR mix and carrying out 2 to 3 additional thermal cycles can clean up DNA that has been over-amplified.

If one primer is more abundant or efficient than the other is, a smaller, single-stranded DNA band or bands may also be present.

The hiatus between carrying out the amplification reaction and running the agarose gel allows the sample to cool to room temperature, and can potentially result in mispriming and the accumulation of replication parasites. However, this is unavoidable and is not as serious for samples that have been partially amplified as it is for samples that are just beginning the amplification procedure. To avoid this potential problem, it is sometimes desirable to take one-fourth to one-third of the selected RNA and carry out a "ranging" $R T-P C R$ reaction to establish the optimal number of cycles for amplification. Another one-fourth to one-third of the selected RNA can then be continuously amplified to this optimum level.

The various controls ("no protein," "no template," "no RT") should be amplified in parallel with the actual sample. If specifically bound RNA is templating the accumulating amplicons, then the "No RT" sample should lag the RT-PCR reaction by at least three cycles. It is devoutly hoped that no bands will be observed in the "no template" control, but if they do arise, they should lag the RT-PCR reaction by at least five cycles. If bands do arise, a distinction should be made between full-length $P C R$ products (indicating contaminating replicons) and smaller products (likely primer amplification artifacts). If product bands in the control lanes are as prominent as product bands in the experimental lanes, then it is necessary to check or remake reagents and go back and repeat the previous round of selection. There is one exception to this rule: in the initial rounds, it is common to see a band in the "no protein" control lane because the proportion of the population that binds to the filter is typically greater than the proportion that binds specifically to the target. However, subsequent rounds of selection should result in the diminution or disappearance of the "no protein" band. 
Although we will consider methods for closely monitoring the progress of the selection experiment, observing the number of thermal cycles needed to visualize a double-stranded DNA band can loosely monitor the progress of the selection. The number of thermal cycles should be roughly proportional to the amount of RNA pool that originally binds to the protein. Therefore, if the RNA eluted from the "no protein" control requires more thermal cycles for full amplification than does the RNA selected in the presence of protein, it can be tentatively assumed that the selected RNA is binding to the protein. Occasionally, in the early rounds of selection, this may not be true, since a very small fraction of the pool will bind to the protein relative to the small fraction of the pool that adheres to the filter.

Counting PCR cycles is, however, only a very rough (and frequently inconsistent) measure of success. In fact, it is common for the number of thermal cycles required to fully amplify selected nucleic acids to vary greatly between rounds. Direct binding assays of the RNA pool (Support Protocol 3) are a much more accurate and useful gauge of the progress of a selection experiment.

6. When a product band does appear, precipitate the PCR reaction by adding an equal volume of $4 \mathrm{M}$ ammonium acetate, and, to the resulting mixture, an equal volume of ethanol (i.e., $2 \times$ the original PCR reaction volume).

If a large amount of sample has been used for gel analysis (for example, if only $50 \mu \mathrm{L}$ of the original RT-PCR reaction remains), then one may wish to return to the selected RNA reservoir and amplify a new DNA template using the already determined "optimal" number of thermal cycles.

\section{Use amplified DNA template for the next round of selection}

7. Centrifuge the sample and resuspend in 10 to $20 \mu \mathrm{L}$ TE buffer. Proceed with the next round of selection starting with step 1 of Basic Protocol 1.

A 100- $\mu$ L RT-PCR reaction yields $\sim 1$ to $2 \mu \mathrm{g}$ DNA, so approximately half of the resuspended $D N A$ sample should be used for the next transcription reaction. The remaining DNA can serve as a long-term, archival sample.

\section{ASSAYING THE ACCUMULATION OF BINDING SPECIES}

In order to verify that the RNA pool has been or is being winnowed to those few sequences that bind the protein target with high affinity and specificity, the selected RNA pool should periodically be assayed for its ability to bind the target protein. The authors recommend an initial binding assay after five rounds of selection and amplification, then again every three additional rounds (the same recommendation that was made with regard to checking for filter-binding species; the two tests can be carried out in parallel). While the initial binding assay is carried out at a series of protein concentrations to gauge the amount of protein that should be used in the selection, the progress of the selection can be most simply monitored by radiolabeling the RNA and determining how much binds to a single, convenient concentration of the protein target.

\section{Materials}

Pool of dsDNA after $n$ rounds of selection

Binding buffer

Target protein

13-mm, 0.45- $\mu \mathrm{m}$ HAWP nitrocellulose disk filters (Millipore)

Filter holders (Nuclepore)

Vacuum manifold

Glass plate

Plastic wrap

Phosphoimager and screen or X-ray film 
Additional reagents and equipment for purifying a radiolabeled DNA pool (see

Basic Protocol 1) and performing the filter binding assay (see Support Protocol 2)

1. Generate radiolabeled RNA pool via a "hot transcription" with $\alpha$-labeled nucleoside triphosphates and purify as described in the final annotation to step 1 of Basic Protocol 1.

2. Thermally equilibrate $1 \mu \mathrm{g}$ of the radiolabeled RNA pool after a round of selection in binding buffer as described in Support Protocol 2, step 2.

3. Add an equimolar amount of protein to the RNA pool. Incubate the binding reaction under conditions similar to those used for selection (see Support Protocol 2, steps 3 and 4).

If the amount of protein sample is limited or limiting, less protein can be used in the binding reaction. However, one should be cognizant of the fact that less than $100 \%$ binding is possible. Alternatively, less protein and less RNA sample can be used, although the diminution of both components will mean that one is assaying binding under conditions more stringent than those actually used for selection. While the volume of the binding reaction could also be diminished to conserve protein, it is difficult to uniformly apply volumes less than $30 \mu \mathrm{L}$ to the filter.

4. Prior to filtration, take a small aliquot of the binding reaction (i.e., $5 \mu \mathrm{L}$ out of a 100 $\mu \mathrm{L}$ binding reaction) to determine the total amount of radioactive RNA in the binding reaction. Pipet the sample onto a nitrocellulose filter disk and set the disk aside on a glass plate.

5. Filter the binding reaction and wash 3 times with $200 \mu \mathrm{L}$ binding buffer (see Support Protocol 2, steps 5 and 6).

6. Place the filters on the glass plate next to the initial aliquots of the binding reaction.

7. Cover the membranes with plastic wrap and expose to a phosphor screen (e.g., Phosphor imager or X-ray film for 4 to $12 \mathrm{hr}$ ).

8. Count the radioactivity using the Phosphorimager or a densitometer and calculate the fraction bound as follows:

Fraction bound $=(\mathrm{cpm}$ of filtered solution $) /[(\mathrm{cpm}$ of aliquot from step 4$) \times($ vol. of filtered solution/vol. of aliquot from step 4)].

A good result at this point would be 0.15 to 0.20 fraction bound above background (see Table 9.3.1. round 6). If binding to filter alone is too high, then filter binders are being selected and more negative selection is needed.

\section{REAGENTS AND SOLUTIONS}

Use deionized, distilled water in all recipes and protocol steps. For common stock solutions, see APPENDIX 2A; for suppliers, see SUPPLIERS APPENDIX.

\section{Denaturing dye, $2 \times$}

TBE buffer (APPENDIX 2A) containing:

$0.1 \%(\mathrm{w} / \mathrm{v})$ bromphenol blue

$7 \mathrm{M}$ urea

In Vitro Selection

of RNA Aptamers

to a Protein

Target by Filter

Immobilization

\section{Denaturing polyacrylamide gel, 10\%}

TBE buffer (APPENDIX 2A) containing:

$10 \%(\mathrm{w} / \mathrm{v})$ acrylamide 
$0.5 \%(\mathrm{w} / \mathrm{v})$ bisacrylamide

$7 \mathrm{M}$ urea

See APPENDIX 3B for full details on pouring and running the gel.

\section{Elution buffer}

$7 \mathrm{M}$ urea

$100 \mathrm{mM}$ sodium citrate

3 mM EDTA

Store up to 3 months at $-20^{\circ} \mathrm{C}$

Prepare with RNase-free water.

PCR mix

$10 \mathrm{mM}$ Tris.Cl, $\mathrm{pH} 8.4$ (APPENDIX 2A)

$50 \mathrm{mM} \mathrm{KCl}$

$1.5 \mathrm{mM} \mathrm{MgCl}{ }_{2}$

$0.2 \mathrm{mM}$ each dNTP

$5 \%(\mathrm{w} / \mathrm{v})$ acetamide

$0.05 \%(\mathrm{v} / \mathrm{v})$ Nonidet P-40 (NP-40)

$0.5 \mu \mathrm{M}$ each primer

0.2 U Taq DNA polymerase (Promega)

RT buffer, $10 \times$

$500 \mathrm{mM}$ Tris. $\mathrm{Cl}, \mathrm{pH} 8.0$ (APPENDIX 2A)

$400 \mathrm{mM} \mathrm{KCl}$

$60 \mathrm{mM} \mathrm{MgCl}_{2}$

Store up to 6 months at $-20^{\circ} \mathrm{C}$

\section{RT-PCR mix}

$10 \mathrm{mM}$ Tris $\cdot \mathrm{Cl}, \mathrm{pH} 8.4$ (APPENDIX 2A)

$50 \mathrm{mM} \mathrm{KCl}$

$1.5 \mathrm{mM} \mathrm{MgCl}_{2}$

$0.2 \mathrm{mM}$ each dNTP

$5 \%(\mathrm{w} / \mathrm{v})$ acetamide

$0.05 \%(\mathrm{v} / \mathrm{v})$ Nonidet P-40 (NP-40)

$0.5 \mu \mathrm{M}$ each primer

$0.2 \mathrm{U}$ Taq polymerase (Promega)

$10 \mathrm{U}$ AMV reverse transcriptase (USB)

\section{Transcription mix}

$40 \mathrm{mM}$ Tris $\cdot \mathrm{Cl}, \mathrm{pH} 7.9$ (APPENDIX 2A)

$26 \mathrm{mM} \mathrm{MgCl}_{2}$

$0.01 \%(\mathrm{v} / \mathrm{v})$ Triton X-100

$2.5 \mathrm{mM}$ spermidine trihydrochloride

$5 \mathrm{mM}$ dithiothreitol

$2.5 \mathrm{mM}$ each ribonucleotide triphosphate

20 U RNasin (Promega)

100 U T7 RNA polymerase (New England Biolabs)

Prepare fresh

\section{COMMENTARY}

\section{Background Information}

Sol Speigelman and coworkers developed a working system for the in vitro replication and evolution of small RNA molecules over 25 years ago (Mills et al., 1967; Levisohn and Spiegelman, 1969; Kramer et al., 1974). The development of more advanced (although conceptually identical) methods for in vitro evolu-
Combinatorial Methods in Nucleic Acid Chemistry 
tion as described in this chapter was potentiated by advances in the chemical synthesis of oligonucleotides and the amplification of nucleic acids, such as PCR, in vitro transcription, and 3SR (Guatelli et al., 1990). The adaptation of these methods to in vitro evolution of RNA molecules was partially due to a recognition that early evolutionary events, such as the genesis of ribozymes, could be recapitulated in a test tube, and partially due to a recognition that the ability to tailor RNA binding species and catalysts might have numerous biotechnological applications. Following the publication of key papers outlining and proving selection technologies (Ellington and Szostak, 1990; Tuerk and Gold, 1990), a much wider array of selection experiments has been attempted. To date, RNA molecules that can bind targets as small as zinc and as large as viruses and organs have been selected. RNA molecules that interact with both nucleic acid-binding proteins and non-nucleic acid binding proteins can be selected with almost equal facility from random sequence populations. These results have been thoroughly reviewed in numerous recent publications (Gold et al., 1995; Uphoff et al., 1996; Famulok and Jenne, 1998).

\section{Critical Parameters}

\section{Choosing protein targets}

As briefly described above, a wide variety of proteins have proven to be successful targets for selection experiments, including enzymes, transcription factors, cytokines, antibodies, and viral capsids (Gold et al., 1995; Uphoff et al., 1996; Famulok and Jenna, 1998). There is no common functional theme uniting these targets, nor can many generalities be drawn regarding their biochemistry or structure. However, it is safe to say that "good" selection targets tend to fall into two classes. First, proteins that normally bind nucleic acids will also be able to extract aptamers from a random sequence pool. The notion of a nucleic acid-binding protein can to some extent be expanded to include proteins that bind nucleotides. For example, kinases and dehydrogenases bind nucleotide cofactors and have proven to be good selection targets.

Second, proteins that for whatever reason contain basic patches in their primary sequences or on their surfaces also frequently yield high-affinity aptamers. For example, many cytokines and other signal-transduction proteins bind heparin or other sulfated oligosaccharides, and can also be used to select aptamers from random sequence populations. The anti-cytokine aptamers frequently bind to the same sites as heparin (Jellinek et al., 1993). Similarly, proteins that bind phosphate or phosphomonoester or phosphodiester bonds frequently have positively charged active sites and can be used to elicit aptamers. For example, anti-phosphatase aptamers have been selected from random sequence pools (Bell et al., 1998).

This is not to say that proteins that do not fall into these categories will of necessity be poor selection targets, merely that they are not sure selection targets. For example, antibodies have frequently proven to be excellent selection targets irrespective of whether or not they bind negatively charged antigens (Keene, 1996). This likely implies that proteins that have large pockets or clefts on their surface are good selection targets. This hypothesis is further bolstered by another line of reasoning. Aptamers selected to bind proteins frequently inhibit protein function. That is, anti-antibody aptamers block interactions with antigens, anti-enzyme aptamers inhibit enzymatic activities, and so forth. This so-called 'homing principle' may be due to the fact that aptamers have to not only form a surface that is chemically complementary to a target, but also must fold into a structure that properly presents the chemically complementary surface. The most informationally parsimonious way to achieve both functions is to fit into a pocket on a target, rather than to form a "grasping" structure that can enfold a surface protrusion of a target. Thus, the most common (and most highly represented) aptamers may be those that fit into surface crevices. In contrast, antibodies have a preformed structure for the presentation of chemically complementary surfaces, and thus can more easily grasp protruding epitopes and less easily fit into surface crevices.

Overall, though, researchers should be guided not so much by these considerations, but by the results of initial binding assays with their particular protein target. If the target binds to the filter (not a given, since small, acidic proteins such as the Rop protein from E. coli will frequently pass through the filter) and shows some affinity for a random sequence pool, then it is highly probable that there will be some sequences or structures within the pool with greatly enhanced affinities for the target.

\section{Choosing a binding buffer}

The binding buffer should promote specific binding of nucleic acids to a protein target. The first consideration in choosing a buffer is to 
identify conditions under which the protein is active, or at least stable. In addition, if the selected nucleic acid species are to eventually be used in a particular environment, the selection buffer should reflect this environment. For example, if the selected nucleic acids are to be expressed in a cell, then the selection buffer should be at physiological $\mathrm{pH}$ and contain physiological ion concentrations. Second, there are a variety of parameters that can be used to make the RNA pool more or less "sticky." These parameters are discussed in much greater detail in the following section on the stringency of selection.

A typical binding reaction is built from one of the commonly used buffers, such as Tris. $\mathrm{Cl}$, phosphate, or HEPES, which can hold the $\mathrm{pH}$ near 6 to 8 , together with 50 to $200 \mathrm{mM} \mathrm{NaCl}$ or $\mathrm{KCl}$ and 1 to $10 \mathrm{mM} \mathrm{MgCl}_{2}$. However, these are merely suggestions, and aptamers have in fact been selected under a variety of buffer conditions. For example, in the selection that targeted bFGF, phosphate-buffered saline was used even though it lacked divalent cations. Similarly, ribozyme selections have been carried out in which a variety of divalent metal ions are mixed, and nascent ribozyme species "decide" which combination of metals most enhance their activities (Lehman and Joyce, 1993). An equivalent strategy could be used for the selection of aptamers.

\section{Selection matrices}

Due to the tremendous ratio of matrix surface area to protein surface area, matrix-binding aptamers can quickly and easily eclipse target-binding aptamers. Proteins are likely captured on nitrocellulose or modified cellulose filters via hydrophobic interactions. Nucleic acids are, by and large, too hydrophilic or charged to be similarly captured. This distinction is the basis for most filter-binding assays. However, the nucleobases of nucleic acids obviously contain large hydrophobic surface areas, and it is easy to select nucleic acids that can present nucleobases and be captured by the filter. Selected filter-binding sequences frequently contain purine (especially guanosine) tracts presented as single-stranded loops or bulges. Interestingly, hydrophobic-binding sequences selected on one hydrophobic matrix are frequently cross-reactive with other hydrophobic matrices: i.e., microtiter plate-binding species can bind tubes and filters, filter-binding species can bind tubes and microtiter plates, and so forth.
In order to avoid filter-binding sequences, the authors have filtered RNA samples multiple times in the absence of protein, and in some cases filtered samples following selection but prior to the RT-PCR step. Matrix-binding sequences can also be avoided by altering the matrices used for selection. For example, techniques such as gel mobility shifts, immunoprecipitation, and affinity chromatography have all been successfully used to sieve pools and select target-binding aptamers (Conrad et al., 1996). If filter-binding species predominate in a population even after appropriate precautions are taken, these alternative selection techniques can be used either to rid the selected population of the filter-binding species or, better yet, to restart the selection. For example, if the immunoprecipitation of RNA:protein complexes has been worked out in advance, then immunoprecipitation can be interspersed with rounds of filter-binding.

Even though the selection of filter-binding sequences can be a problem, filter binding is still generally recommended as the technique of choice for most selections. Gel mobility shift experiments tend to be much more sensitive to parameters such as sample preparation, ionic strength, $\mathrm{pH}$, and electrophoresis conditions than are filter-binding experiments. Moreover, just as filter-binding species can be inadvertently selected during filtration selection, RNA species with altered electrophoretic mobilities (e.g., dimers) can be selected during gel-mobility shift selections. Immunoprecipitation experiments require an additional protein reagent and in consequence anti-antibody rather than anti-target aptamers are frequently selected. Affinity chromatography or similar techniques generally require that very large amounts of target proteins be committed to the preparation of affinity matrices. If affinity elution is to be used, then even larger amounts of target proteins will be required. Moreover, aptamers that bind to agarose matrices can be selected almost as easily as aptamers that bind to nitrocellulose or modified cellulose filters (although the two, thankfully, do not cross-bind to one another's matrices). Finally, microtiter plate panning selections encourage the accumulation of the same sorts of matrix-binding aptamers that are elicited by filter-binding selections.

\section{Stringency of selection}

Overall, most selection experiments are generally competitions between specifically and nonspecifically binding nucleic acid species. The authors tend to initially choose con-
Combinatorial Methods in Nucleic Acid Chemistry 
servative binding conditions in hopes of promoting the early establishment of binding species in the population. While this may mean that low-affinity species are isolated from the pool along with high-affinity species, the lowaffinity species can eventually be removed by increasing the stringency of selection. In essence, time (the number of cycles required to purify high-affinity species) can be traded for the assurance that filter-binding species will not accumulate and predominate.

A variety of parameters can be modulated in order to increase or decrease the stringency of a selection experiment. These parameters should initially be chosen based on the results of Support Protocol 2, which assays the affinity of the pool for the target and should be made progressively more stringent based on the results of Support Protocol 3.

The amount of protein target. The more protein there is to bind, the easier it is to capture nucleic acid binding species. Using low amounts of protein increases competition among binding species. However, the amount of protein target available to researchers is usually limited, and thus it is easier to use a set amount of protein (usually from 0.1 to $10.0 \mu \mathrm{m}$ per binding reaction) and to vary the RNA:protein ratio.

RNA:protein ratio. By increasing the ratio of pool to target, more binding species will compete for a smaller number of targets. Typically, after a few initial rounds with an equimolar pool-to-target ratio, the ratio is increased to between 10:1 and 100:1. This increase can be effected either by increasing the amount of RNA or by decreasing the amount of protein. Because of the underlying competition between specifically binding species and nonspecifically binding species, increasing the amount of RNA is preferable to decreasing the amount of protein. For a more detailed treatment of this subject, see Irvine et al. (1991). However, the general conclusions of these mathematical models are similar to the empirical advice given here.

Competitors. High concentrations of nonspecific, non-amplifiable competitors such as tRNA or bulk cellular RNA will compete with low-affinity binding species that adhere to basic patches on the surface of a protein. Typically, a 100 -fold excess of tRNA is used. Similarly, specific competitors can be used to block the access of low-affinity binding species to a preferred site. Wild-type nucleic acid ligands can be used to block the binding sites of nucleic acid binding proteins. For example, during the selection of anti-Rev aptamers, Giver et al. (1993) included a 10-fold excess of the wildtype Rev-binding element. The anti-Rev aptamers that were obtained could bind with high affinity to the RNA-binding domain of Rev and could effectively compete with the wild-type Rev-binding element. Other ligands or substrates can also be used to block the binding or catalytic sites of non-nucleic acid binding proteins. For example, during the selection of antibFGF aptamers, Jellinek et al. (1993) included heparin, a natural ligand for bFGF. The antibFGF aptamers that were obtained could bind with high affinity to the heparin binding site and could effectively compete with heparin.

Cation concentration. Monovalent cations (such as $\mathrm{Na}^{+}$) and divalent cations such as $\mathrm{Mg}^{2+}$ stabilize the structure of RNA molecules and contribute to both specific and nonspecific binding. Decreasing monovalent and/or divalent cation concentrations therefore can therefore increase the stringency of the selection. However, it is unclear, in advance, whether specific or nonspecific binding species will be more favored by such a change. Moreover, since binding species that require a monovalent and/or divalent cation to fold into shapes that are chemically complementary to a target may be favored in the early rounds of selection, potentially high-affinity binding species may be lost by changing the binding buffer late in the selection experiment. It is better to attempt to change the buffer dependency of aptamers by partial randomization and re-selection following the initial selection experiment, rather than to attempt to change the buffer dependency during the selection.

Conversely, higher concentrations of monovalent cations (generally sodium or potassium) increase the structural integrity of folded nucleic acids by neutralizing the close approach of nucleic acid strands. However, higher monovalent ion concentrations also suppress electrostatic interactions with targets. Thus, paradoxically, both "low" and "high" monovalent ion concentrations can be used to increase the stringency of a selection experiments. Higher concentrations of divalent cations such as magnesium help to maintain the structural integrity of RNA molecules and potentially facilitate the formation of salt bridges between acidic residues and the phosphate backbone.

Equilibration time. Longer equilibration times give stronger binding species a greater chance to bind to the target, since weaker binding species more quickly dissociate from the target. In general, though, species with nano- 
molar dissociation constants or lower can be readily selected by allowing the reaction to equilibrate for $5 \mathrm{~min}$ or more. The authors usually allow up to $30 \mathrm{~min}$ for the binding reaction in order to allow for slow folding or refolding steps in the presence of the target. However, longer equilibration times may not be possible for proteins that are inherently unstable or that themselves undergo slow, bufferor temperature-induced conformational changes.

Dilution of binding buffer. Similarly, diluting the binding reaction by 10 - to 20 -fold just prior to filtration will favor the selection of RNA:protein complexes with low dissociation constants over RNA:protein complexes with higher dissociation constants. Baskerville et al. (1995) have successfully used this technique to select high affinity anti-Rex aptamers.

Amount and composition of wash. Increasing the number of times a filter is washed and the volume of the buffer used for the washes should preferentially increase the retention of high-affinity binding species relative to low-affinity and nonspecific binding species. It is generally recommended that the same buffer be used for selection and for wash steps, in order to avoid changing the conditions under which aptamers are selected. However, the stringency of the selection can potentially be manipulated by changing the buffer used for the wash steps. For example, if monovalent cation concentrations are limited in the binding buffer due to requirements for the stability or activity of a protein target, a separate wash buffer that contains a higher salt concentration can be used to challenge captured RNA:protein complexes.

\section{Parasites}

Replication parasites differ from matrixbinding aptamers, but can interfere with the selection of target-binding aptamers in the same way. Reverse transcriptase, Taq polymerase, and T7 RNA polymerase all have some preference for which sequences they will copy or reproduce. These preferences are generally not obvious when constant sequence nucleic acids are being synthesized. However, in selection experiments many cycles of amplification are carried out, and differences in the rates of synthesis are also proportionately amplified, leading to the selection of sequences that have no function other than to replicate optimally. For example, during the polymerase chain reaction if a primer designed to bind to a constant sequence region instead recognizes a partially complementary sequence within a random se- quence region, it can set down and generate a smaller amplicon. The smaller amplicon will generally be amplified more quickly than the larger amplicon, and thus can potentially outcompete full-length species selected for binding function. Depending on the relative advantage of the replication parasite relative to an aptamer, even if the replication parasite is partially removed from the population during each selection step, enough molecules may remain to overrun the amplification reaction and displace the functionally selected aptamer. This is especially true if the amplification parasite also happens to be a filter-binding species. It is for this reason that the authors of this unit strongly recommend that DNA templates and/or RNA molecules be size-selected in each round.

The nascent reproductive differences between nucleic acid species can be grossly amplified by amplification methods that allow continuous reproduction of the nucleic acids, such as isothermal amplification or 3SR (Guatelli et al., 1990). For example, Breaker and Joyce (1994) generated an extremely robust replication parasite, RNA Z, during a selection designed to generate catalytic variants of a group II intron. Similarly, the authors have generated replication parasites of isothermal amplification reactions from completely random sequence pools (K. Marshall, pers. comm.). Interestingly, these isothermal amplification parasites were actually larger than the initial RNA species and represented recombination events between individual members of the pool. Airborne copies of these replication parasites can readily "seed" isothermal amplification reactions and overrun pool molecules that are initially present in even million-fold excess. In this respect, the replication parasites of isothermal amplification reactions resemble the midi-variants or "monsters" of $Q \beta$ replicase amplification reactions, and are equally hard to vanquish, once established. It is for this reason that the authors strongly recommend the sometimes tedious but inherently faithful regime of reverse transcription, PCR, and in vitro transcription for the amplification of RNA pools. However, successful selections have been carried out that have relied upon isothermal amplification (see, for example, Breaker et al., 1994; Wright and Joyce, 1997; Wlotzka and McCaskill, 1997), and this admonition can most confidently challenged if the starting pool is a partially randomized binding site or ribozyme. The reason is that isothermal amplification parasites are more likely to be found in or derived from a "deep random" pool than in
Combinatorial Methods in Nucleic Acid Chemistry 
a pool that centers on a given functional sequence.

\section{Anticipated Results}

Table 9.3.1 shows the progression of a selection carried out in the authors' lab against bFGF with an RNA pool with a 30 nucleotide randomized region. In order to evaluate the success of a selection experiment, it was necessary to compare the affinity of the selected pool versus the affinity of the unselected pool for the protein target (Support Protocol 3). When assaying the pool after a round of selection, it was necessary to validate the fraction of the pool that bound to the protein by including a no protein control. If the accumulation of matrix-binding species had been evident, more stringent negative selections could have potentially been used to control or reduce their numbers.

\section{Time Considerations}

The time required to go from one pool of selected DNA templates to the next is $\sim 24$ to $72 \mathrm{hr}$, depending on the researcher and the demands of the particular selection experiment. Minimally, a transcription reaction takes $\sim 4 \mathrm{hr}$, and the ensuing DNAse, heat denaturation and gel purification steps can take another 2 to $3 \mathrm{hr}$. Elution for 8 to $10 \mathrm{hr}$ yields an adequate amount of RNA to be used it the subsequent binding reaction. After precipitation and quantification of the RNA (1 hr), the preselection filtration, incubation with target, and selection steps can be performed in $2 \mathrm{hr}$. Elution of protein-RNA complexes, subsequent extractions, and another precipitation step take another $2 \mathrm{hr}$. The amount of time needed to see a DNA product varies according to the number of PCR cycles needed to amplify the pool to a certain amount, and that number is inversely related to the abundance of target-binding species that survived the selection. Nevertheless, the RT-PCR steps, followed by precipitation of the DNA templates that can be added to the transcription mix, should consume $\sim 3$ to $4 \mathrm{hr}$.

The amount of time it takes to carry out the entire selection is contingent upon the number of rounds needed to accumulate target-binding species. That number, in turn, varies depending upon the initial affinity of the unselected pool for the target and on the stringency with which each round of the selection is carried out. When additional steps such as radiolabeling and assaying unselected and selected pools are taken into account, an entire selection experiment can take up to 2 to 3 weeks. It is for this reason that the authors have recently developed automated methods for selection experiments (Cox et al., 1998) that can speed the entire process by an order of magnitude.

\section{Literature Cited}

Baskerville, S., Zapp, M., and Ellington, A.D. 1995. High resolution mapping of the human T-cell, leukemia virus type 1 rex-binding element by in vitro selection. J. Virol. 69:7559-7569.

Bell, S.D., Denu, J., Dixon, J.E., and Ellington, A.D. 1998. RNA molecules that bind to and inhibit the active site of a tyrosine phosphatase. J. Biol. Chem. 273:14309-14314.

Breaker, R. and Joyce, G.F. 1994. Emergence of a replicating species from an in vitro RNA evolution reaction. Proc. Natl. Acad. Sci. U.S.A. 91:6093-6097.

Breaker, R., Banerji, A., and Joyce, G.F. 1994. Continuous in vitro evolution of bacteriophage RNA polymerase promoters. Biochemistry 33:1198011986.

Conrad, R.C., Giver, L., Tian, Y., and Ellington, A.D. 1996. In vitro selection of nucleic acid aptamers that bind proteins. Methods Enzymol. 267:336367.

Cox, J.C., Rudolph, P., and Ellington, A.D. 1998. Automated DNA selection. Biotechnol. Prog. 14:845-850.

Ellington, A.D. and Szostak, J.W. 1990. In vitro selection of RNA molecules that bind specific ligands. Nature 346:818-822.

Famulok, M and Jenne, A. 1998. Oligonucleotide libraries--variatio delectat. Curr. Opin. Chem. Biol. 2:320-327.

Giver, L., Bartel, D., Zapp, M., Green, M., and Ellington, A.D. 1993. Selective optimization of the Rev-binding element of HIV-1. Nucl. Acids Res. 23:5509-5516.

Gold, L., Polisky, B., Uhlenbeck, O., and Yarus, M. 1995. Diversity of oligonucleotide functions. Annu. Rev. Biochem. 64:763-797.

Guatelli, J., Whitfield, K., Kwoh, D., Barringer, K.J., Richman, D., and Gingeras, T.R. 1990. Isothermal, in vitro amplification of nucleic acids by a multienzyme reaction modeled after retroviral replication. Proc. Natl. Acad. Sci. U.S.A. 87:1874-1878.

Irvine, D., Tuerk, C., and Gold, L. 1991. SELEXION: Systematic evolution of ligands by exponential enrichment with integrated optimization by non-linear analysis. J. Mol. Biol. 222:739761.

Jellinek, D., Lynott, C., Riata, D., and Janjic, N. 1993. High affinity RNA ligands to basic fibroblast growth factor inhibit receptor binding. Proc. Natl. Acad. Sci. U.S.A. 90:11227-11231.

Keene, J.D. 1996. RNA surfaces as mimetics of proteins. Chem. Biol. 3:505-513. 
Kramer, F.R., Mills, D.R., Cole, P.E., Nishihara, T., and Speigelman, S. 1974. Evolution of in vitro sequence and phenotype of a mutant RNA resistant to ethidium bromide. J. Mol. Biol. 89:719736.

Lehman, N. and Joyce, G.F. 1993. Evolution in vitro of an RNA enzyme with altered metal dependence. Nature 361:182-185.

Levisohn R. and Spiegelman, S. 1969. Further extracellular Darwinian experiments with replicating RNA molecules: Diverse variants isolated under different selective conditions. Proc. Natl. Acad. Sci. U.S.A. 63:805-811.

Mills, D.R., Peterson, R.L., and Speigelman, S. 1967. An extracellular Darwinian experiment with a self-duplicating nucleic acid molecule. Proc. Natl. Acad. Sci. U.S.A. 58:217-224.

Tuerk, C. and Gold, L. 1990. Systematic evolution of ligands by exponential enrichment: RNA ligands to bacteriophage T4 DNA polymerase. Science 249:505-510.

Uphoff, K., Bell, S., and Ellington, A.D. 1996. In vitro selection of aptamers: The dearth of pure reason. Curr. Opin. Struct. Biol. 6:281-288.
Wlotzka, B. and McCaskill, J.S. 1997. A molecular preator and its prey: Coupled isothermal amplification of nucleic acids. Chem. Biol. 4:25-33.

Wright, C. and Joyce, G.F. 1997. Continuous in vitro evolution of catalytic function. Science 276:614617.

\section{Key References}

Conrad et al., 1996. See above.

Conrad, R.C., Brück, F.M., Bell, S., and Ellington, A.D. 1998. In vitro selection of nucleic acid ligands. In Nucleic Acid-Protein Interactions: A Practical Approach (W.J. Christopher, ed.). Oxford University Press, New York, pp. 285-315.

The above two papers also provide protocols for the selection of aptamers via filter immobilization as well as by other means.

Contributed by Sulay D. Jhaveri and Andrew D. Ellington

University of Texas

Austin, Texas
Combinatorial

Methods in

Nucleic Acid

Chemistry 